\title{
Hyperthermic intraperitoneal chemotherapy (HIPEC) for ovarian cancer recurrence: systematic review and meta-analysis
}

\author{
Stefano Cianci ${ }^{1}$, Gaetano Riemma ${ }^{1}$, Carlo Ronsini ${ }^{2}$, Pasquale De Franciscis ${ }^{1}$, Marco Torella ${ }^{1}$, \\ Antonio Schiattarella ${ }^{1}$, Marco La Verde ${ }^{1}$, Nicola Colacurci ${ }^{1}$ \\ ${ }^{1}$ Department of Woman, Child and General and Specialized Surgery, University of Campania "Luigi Vanvitelli", Naples, Italy; ${ }^{2}$ Gynecologic and \\ Obstetrics Unit, Università “G. d'Annunzio”, Chieti, Italy \\ Contributions: (I) Conception and design: All authors; (II) Administrative support: S Cianci, G Riemma; (III) Provision of study materials or patients: \\ None; (IV) Collection and assembly of data: S Cianci, G Riemma, C Ronsini; (V) Data analysis and interpretation: All authors; (VI) Manuscript \\ writing: All authors; (VII) Final approval of manuscript: All authors. \\ Correspondence to: Stefano Cianci, MD, PhD. Department of Woman, Child and General and Specialized Surgery, University of Campania "Luigi \\ Vanvitelli”, Largo Madonna delle Grazie, 180138 Naples, Italy. Email: stefano.cianci@unicampania.it.
}

\begin{abstract}
Background: Ovarian cancer is the first cause of death among gynecological malignancies with a high incidence of recurrence. Different treatment options are suitable to prolong the survival rate of these patients. Over the last years, one of the most intriguing methods, adopted in different oncologic centers worldwide, is the hyperthermic intraperitoneal chemotherapy (HIPEC).

Methods: A meta-analysis was performed to value the role of HIPEC for ovarian cancer recurrence. Search strategy was conducted with a combination of the following keywords: "ovarian recurrence, ovarian cancer recurrence, peritoneal cancer recurrence, ovarian recurrence AND HIPEC, secondary cytoreduction HIPEC”. Seven studies were selected for analysis.

Results: In women with recurrent ovarian cancer (ROC), the use of HIPEC in addition to cytoreductive surgery and chemotherapy significantly improved 1-year overall survival (OS) when compared to protocols without HIPEC (OR 2.42; 95\% CI, 1.06-5.56; $\mathrm{P}=0.04 ; \mathrm{I}^{2}=4 \%$ ). The improvement in OS was maintained significant also after 2, 3 and 5 years respectively (OR 3.33; 95\% CI, 1.81-6.10; $\mathrm{P}<0.01 ; \mathrm{I}^{2}=0 \%$ ), (OR 4.22; 95\% CI, 2.07-8.60; P<0.01; $\mathrm{I}^{2}=52 \%$ ), (OR 5.17; 95\% CI, 1.40-19.09; P=0.01; $\mathrm{I}^{2}=82 \%$ ).
\end{abstract}

Conclusions: HIPEC seems to have an effective role to prolong survival in patients affected by ROC.

Keywords: Ovarian cancer; hyperthermic intraperitoneal chemotherapy (HIPEC); loco-regional treatment; peritoneal carcinosis; recurrence; chemotherapy

Submitted Mar 11, 2020. Accepted for publication Jun 03, 2020.

doi: $10.21037 /$ gs-20-335

View this article at: http://dx.doi.org/10.21037/gs-20-335

\section{Introduction}

Ovarian cancer is the first cause of death among gynecologic malignancies (1). The surgical treatment represents the first option with the aim to achieve the optimal debulking, followed by systemic chemotherapy (2). However, even achieving complete cytoreduction the majority of patients at stage III-IV develops a recurrence in a few years (3). To date, different treatment options are suitable to prolong the survival rate of these patients as monoclonal antibodies and targeted therapies as bevacizumab or PARP inhibitors, and biological therapy. However, the results obtained are still partial and not completely effective (4). One of the most attractive methods, currently available in several oncologic centers, is the hyperthermic intraperitoneal chemotherapy (HIPEC). It is an effective method to deliver antiblastic drugs directly in the abdomen at the time of surgery, moreover the hyperthermia addiction allowed to enhance the tissue absorption, that is different depending on different factors as drugs administered and 


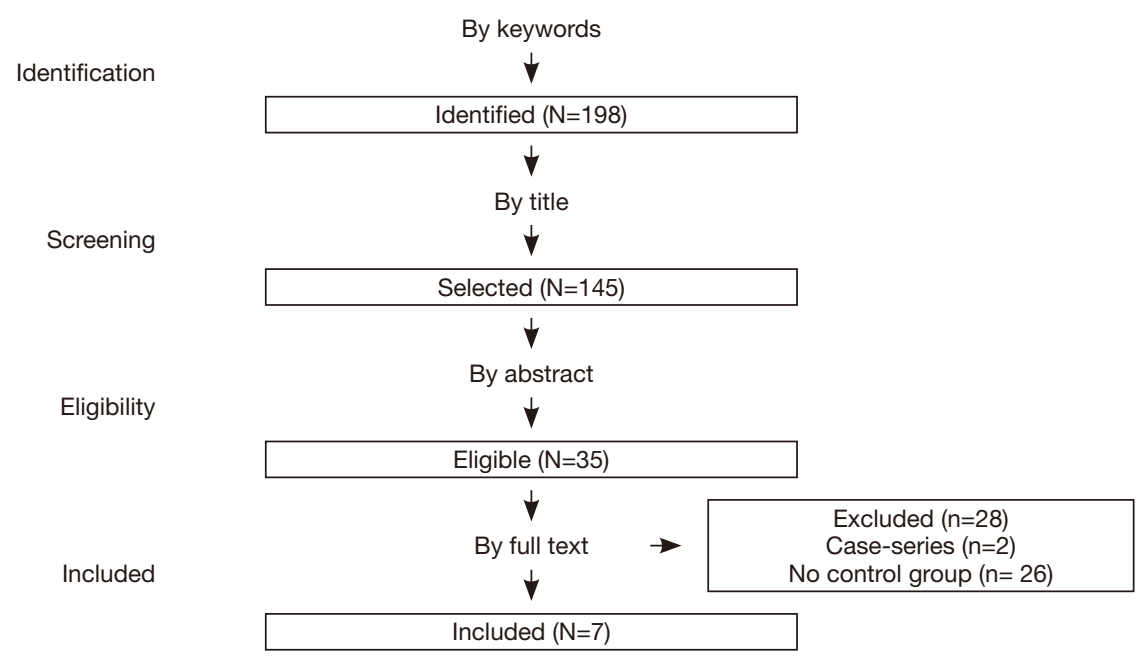

Figure 1 Study selection search strategy.

temperature reached, and consequently the cytotoxic action of chemotherapeutic drugs that reach the maximum effect between 40 and 43 centigrade (5). HIPEC treatment is adopted in different kind of cancer as gastric, colorectal and primary peritoneal carcinosis. For ovarian cancer treatment, this technique, was for a long time debated, however after the results of a randomized trial by van Driel et al. (6) HIPEC was inserted in NCCN guidelines as an optional treatment for interval debulking surgery (NCCN clinical practice guidelines Version 1.2019-March 8, 2019 OV-2).

The role of HIPEC in treatment of primary ovarian cancer (POC) and recurrent ovarian cancer (ROC) is actually under study. Different series could be found in literature, and different on-going trials (HORSE NCT01539785, CHORINE NCT01628380, HIPOVA01NCT03220932). However, the heterogeneity of the population and the different drugs administered did not allow to draw definitive conclusions.

The present study aims to explore whether the addition of HIPEC in ROC patients could improve clinical outcome. A systematic review of the literature and meta-analysis was performed. We present the following article in accordance with the PRISMA reporting checklist (available at http:// dx.doi.org/10.21037/gs-20-335).

\section{Methods}

We performed our meta-analysis following the Preferred Reporting Items for Systematic reviews and Meta-Analyses (PRISMA) (7) and the Meta-analysis Of Observational Studies in Epidemiology (MOOSE) statement guidelines (8). The research protocol was designed a priori, defining methods for literature search, article examination and inclusion criteria, data extraction and analysis.

\section{Search strategy}

Searches were performed using PubMed, Scopus, and Cochrane from the inception of all databases until March 2020. We searched the databases with a combination of the following keywords and Medical Subject Headings (MeSHs): "ovarian recurrence, ovarian cancer recurrence, peritoneal cancer recurrence, ovarian recurrence AND HIPEC, secondary cytoreduction HIPEC", without restricting our search geographically or linguistically. The PRISMA based flow-diagram in Figure 1 depicts our search strategy. If it was necessary, we obtained unpublished data by contacting authors of the original papers whenever methodology indicated that further outcome data were recorded.

\section{Study selection and outcomes}

We included all studies with more than ten patients comparing women with a diagnosed first recurrent ovarian epithelial cancer treated with cytoreductive surgery and HIPEC protocols versus cytoreductive surgery without HIPEC.

Moreover, we excluded commentaries, editorials, reviews, letters and abstracts. 
Two authors (CR and GR) reviewed and classified all abstracts independently. The agreement about potential relevance was reached by consensus of the researchers; the same two authors were able to obtain full-text copies of those papers and separately extracted relevant data regarding study characteristics and outcomes. Later, the two reviewers discussed all the inconsistencies; and, if needed, a third author (SC) decided if no consensus was reached.

If more than one study was published on the same cohort and with the same identical endpoints, population overlapping was avoided considering only the article with the most comprehensive information.

Two different authors (GR and AS) assessed the risk of bias of all studies included in this review. The Modified Newcastle-Ottawa Scale for case-control studies was used for observational studies; The Cochrane risk of bias tool was used to assess the risk of the included RCTs. In case of disagreement, a third reviewer (SC) judged. Potential publication bias was assessed by the Egger's test. The articles remained were then filtered according with the availability for meta-analysis.

The primary outcome of the meta-analysis was the oneyear overall survival (OS). Secondary outcomes explored were the two, three and five-year OS.

\section{Statistical analysis}

Pooled odds ratios (ORs) and $95 \%$ confidence interval (CI) were calculated using the Der Simonian and Laird random-effects model. We quantified heterogeneity to describe the percentage of total variation across studies attributable to heterogeneity rather than by chance by means of Higgins $\mathrm{I}^{2}$-statistic. In our meta-analysis, $\mathrm{I}^{2}$-values of $25 \%, 50 \%$ and $75 \%$ corresponded to cut-off points for low, moderate and high degrees of heterogeneity. We used Review Manager 5.3 (The Nordic Cochrane Centre 2014, Copenhagen, Denmark) and Stata 14.1 (Stata corp., College Station, TX, 2013) to analyze data. For studies in which the corresponding results were not shown, the Engauge Digitizer v.4.1 software was used to extract survival data obtained from the Kaplan-Meier curves.

\section{Results}

\section{Study selection and study characteristics}

We identified and assessed 198 initial studies (Figure 1). Of those, 26 studies were considered pertinent for the study criteria, seven of them were considered available for meta- analysis. Depicts summary characteristics of included studies Table 1. Those seven studies regarded women with ROC treated with or without HIPEC. Concerning the included studies, they were conducted in France, Spain, Italy, Israel, Brazil and Egypt between 2009 and 2019. We identified one RCT (9), one prospective (10) and five retrospective casecontrol studies (11-15).

Drugs used for HIPEC chemotherapy, as well as temperature and duration, were described in every study. The most used HIPEC chemotherapy was cisplatin. It was used in combination with other agents such as doxorubicin, mitomycin-C or paclitaxel. One study used carboplatin in combination with paclitaxel or doxorubicin (12). One research involved the use of oxaliplatin alone (10). Mean temperature for HIPEC was between $41-41.5^{\circ} \mathrm{C}$.

Quality assessment of studies, with the NewcastleOttawa Scale and the Cochrane Tool, showed an overall good score regarding the selection and comparability of the study groups, as well as for ascertainment of the outcomes of interest in case-control studies. For the RCT (9) quality assessment revealed a low risk of bias in 5/7 analyzed elements (Tables $S 1, S 2)$.

\section{Synthesis of the results}

The data are summarized in Table 2. In women with ROC, the use of HIPEC in addition to cytoreductive surgery and chemotherapy significantly improved 1-year OS when compared to protocols without HIPEC (OR 2.42; 95\% CI, 1.06-5.56; $\mathrm{P}=0.04 ; \mathrm{I}^{2}=4 \%$ ) (Figure 2). The improvement in OS was maintained significant also after 2, 3 and 5 years respectively (OR 3.33; 95\% CI, 1.81-6.10; $\mathrm{P}<0.01 ; \mathrm{I}^{2}=0 \%$ ), (OR 4.22; 95\% CI, 2.07-8.60; $\mathrm{P}<0.01 ; \mathrm{I}^{2}=52 \%$ ), (OR 5.17; $95 \%$ CI, 1.40-19.09; $\mathrm{P}=0.01 ; \mathrm{I}^{2}=82 \%$ ) (Figure 3). For the primary outcome, between-studies heterogeneity was referred as low.

\section{Publication bias}

Assessment of publication bias using the Egger's regression model showed that publication bias for small studies was not present for 1-year $(\mathrm{P}=0.22), 2$-year $(\mathrm{P}=0.38)$, 3-year $(\mathrm{P}=0.51)$ and 5 -year $(\mathrm{P}=0.10) \mathrm{OS}$.

\section{Perioperative mortality and complications}

Regarding perioperative mortality between 1 and 30 days after surgery plus HIPEC, reported rates were $4 \%$ 


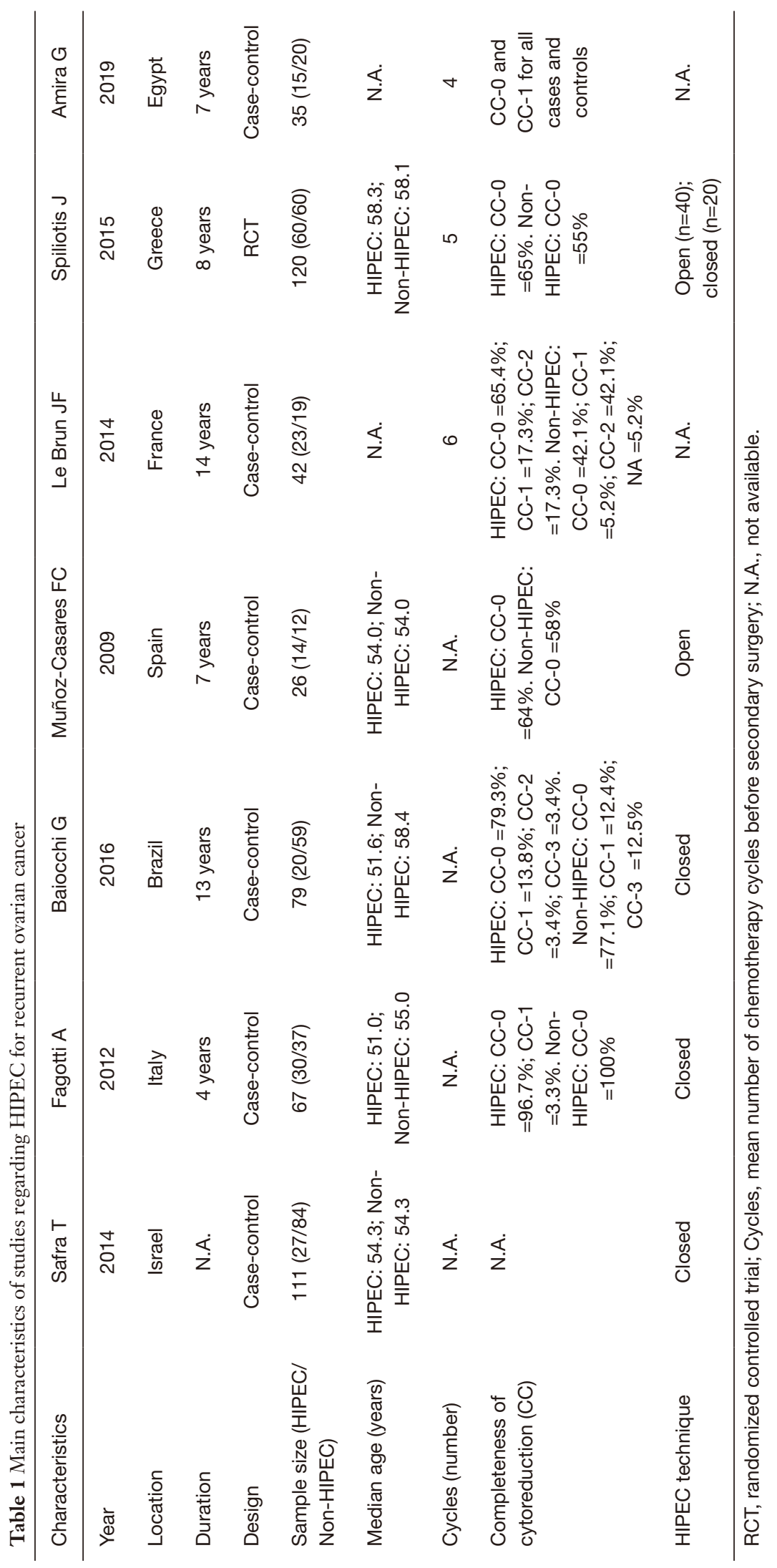




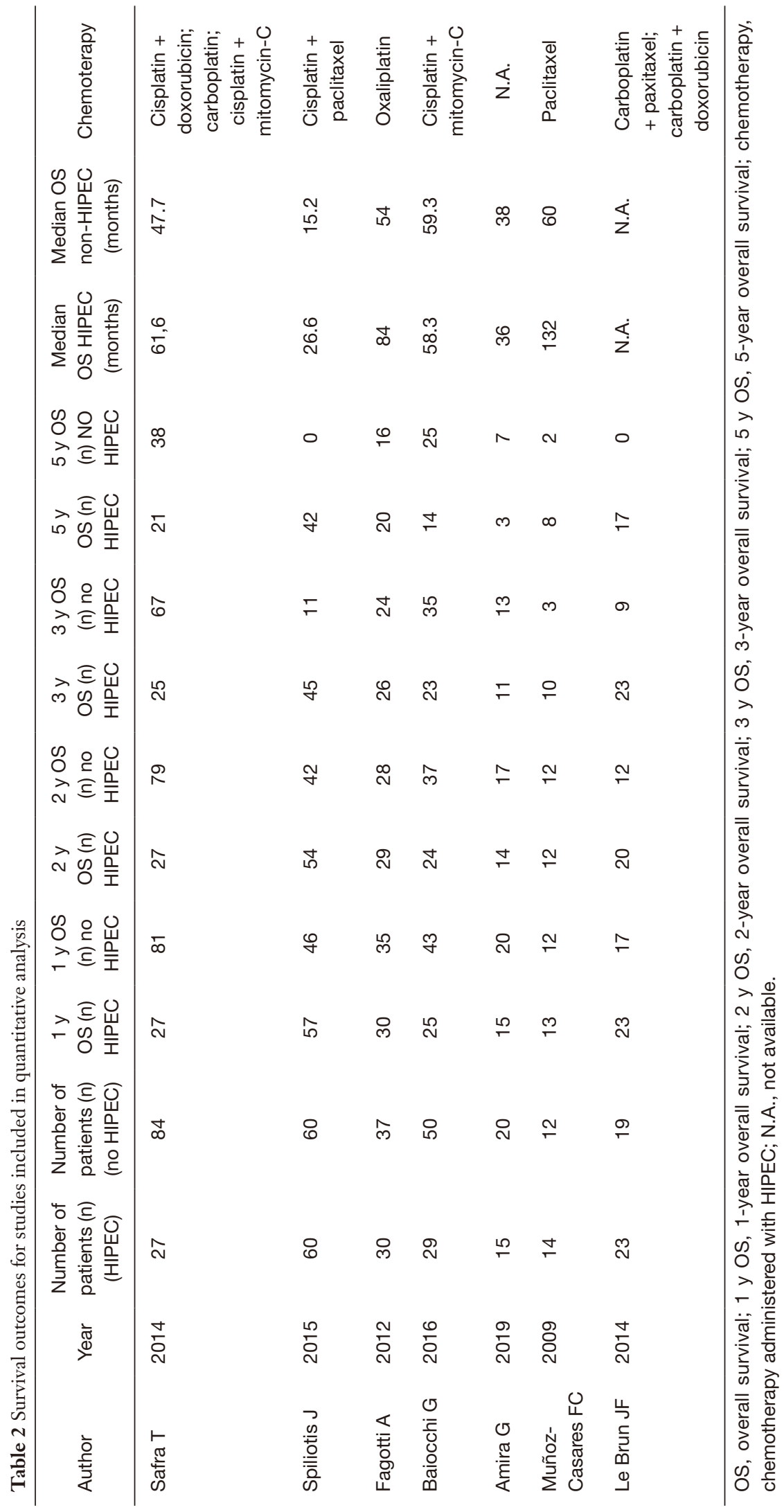




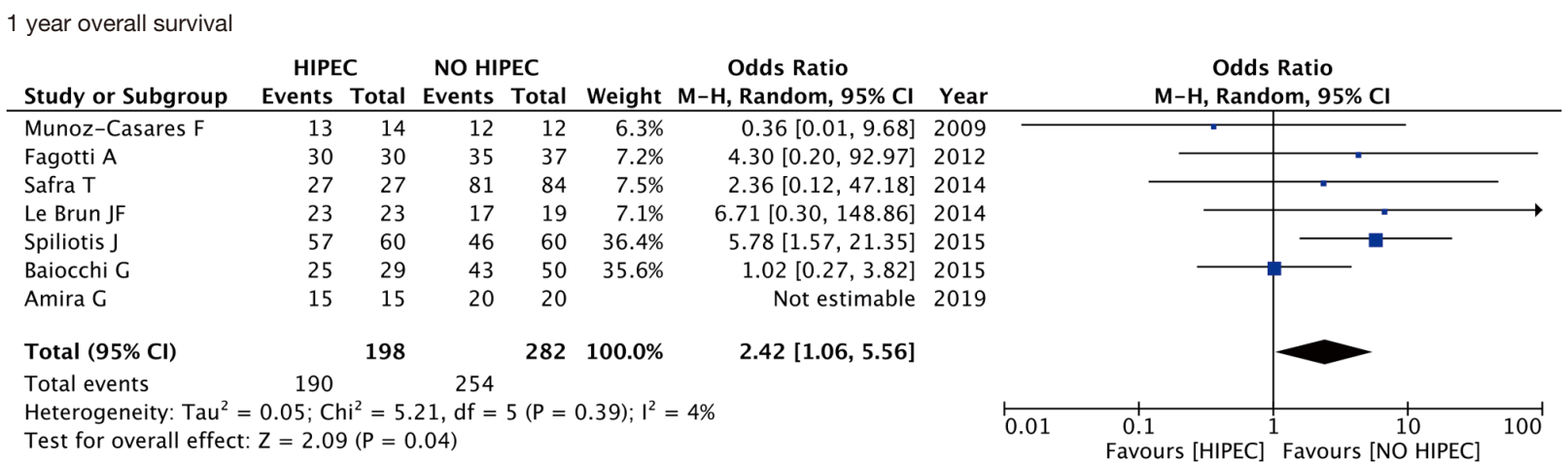

Figure 2 One-year OS forest plot.

in Baiocchi et al. (13), $13.3 \%$ in Amira et al. (14) No perioperative deaths were reported in 4 studies (9-12). Postsurgical hospital stays ranged between 5.1 and 25.8 days, with a 15.9 day calculated mean.

Common adverse reactions after intervention were reported by two studies without distinction between cases and controls $(11,14)$. Amira et al. (14) reported a $53 \%$ of chemotherapy-related toxicity, followed by pulmonary complications (33\%) need for mechanical ventilation; $13 \%$ chest infections). Almost 20\% of women experienced wound infection after surgery. The most common side effect reported by Safra et al. (11) was related to chemotherapy, with mild nausea which was successfully treated by antiemetics. No complications were reported in other studies included in quantitative analysis.

\section{Discussion}

The role of HIPEC for ovarian cancer treatment, seems to furnish clear benefits. Even if the literature remains partially controversial (16).

The randomized trial conducted by van Driel et al. (6) demonstrated the effective role of HIPEC to prolong the survival rate of patients with diagnose of POC submitted to interval debulking surgery. However, the present study was focused on a different subset of patients affected by ROC. Actually, no concrete randomized studies are available regarding this patient's subset. An Italian randomized trial HORSE (NCT01539785) is actually in a follow-up phase, awaiting the results.

A randomized trial by Spiliotis et al. was published (9); however, it was not sufficient to furnish concrete conclusions about the usefulness of HIPEC for ROC.

Considering the most relevant literature available about
HIPEC and ROC, in a study by Petrillo et al. (17), a longterm follow-up series of patients with ROC submitted to secondary cytoreductive surgery and HIPEC was studied with a median follow-up of 5 and 7 years. The results of the study suggested the benefits of HIPEC in terms of longterm survival rates.

Considering our meta-analysis, the results seem very encouraging since the $\mathrm{OS}$ at $1,2,3$ and 5 years were statistically significative in favor of HIPEC groups. However, the limits are related to the heterogeneity of treatments in terms of drugs used and protocol adopted for HIPEC. Moreover, surgical treatment and the achievement of complete debulking remain a fundamental step. Another limitation of our quantitative analysis is related to the design of included studies; the majority were retrospective case-control studies and only one research was a prospective randomized trial. Moreover, the small number of samples in selected studies should be taken into account.

However even, acknowledging such limitations, the results of the meta-analysis were statistically significant in favor of HIPEC, especially for the two years follow-up $(\mathrm{P}<0.0001)$.

In a similar meta-analysis published in 2015 by Huo et al. (18) the authors obtained similar conclusions. Considering this aspect, the accordance of two different studies performed in different periods reinforce the scientific evidence.

Some relevant studies reported an average of 60 months survival rate for selected patients submitted to secondary cytoreductive surgery for ovarian cancer $(19,20)$; these data are in line with our results.

The complexity of surgery can be related to the disease dissemination influencing the surgical invasiveness and the risk of complications. Considering that even if the HIPEC 


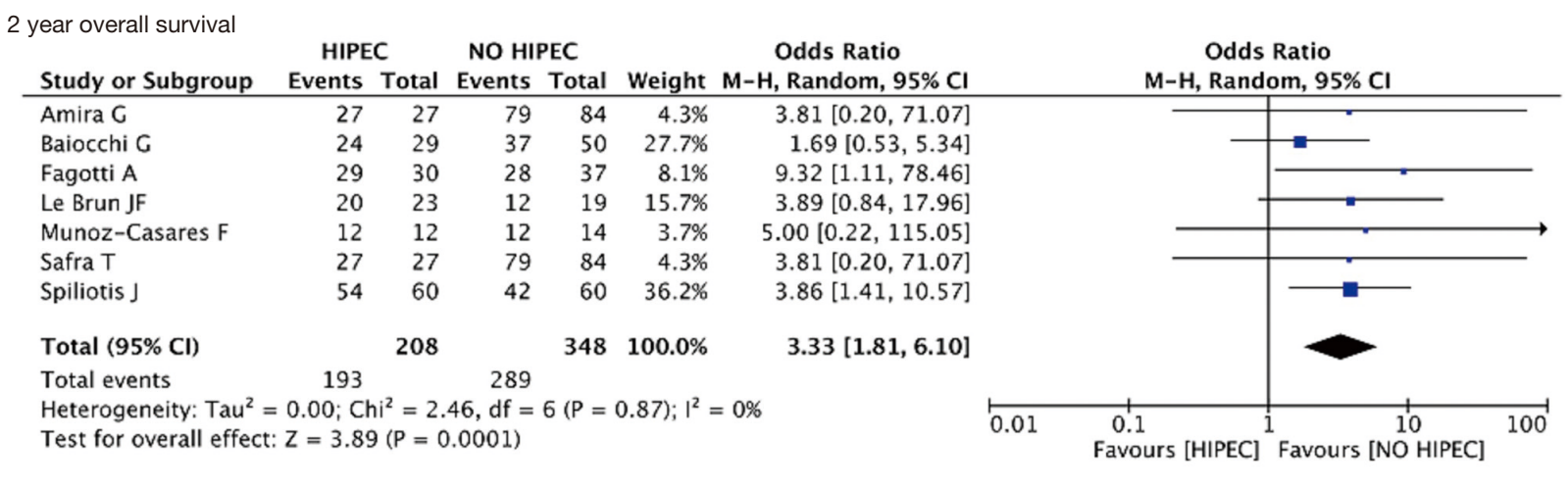

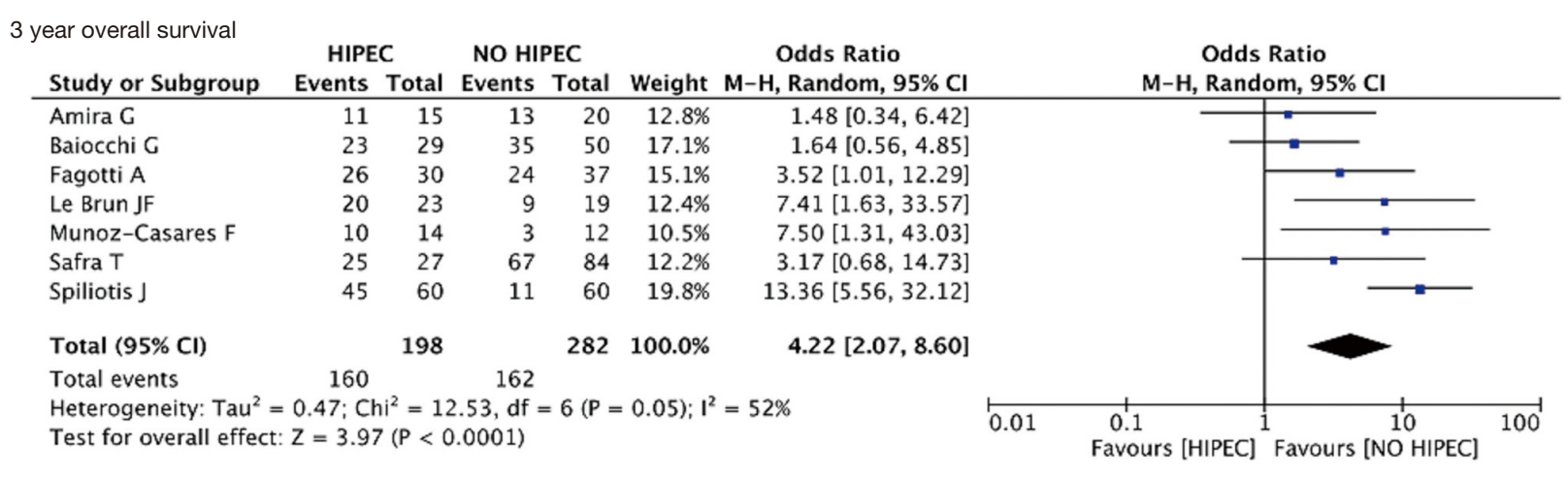

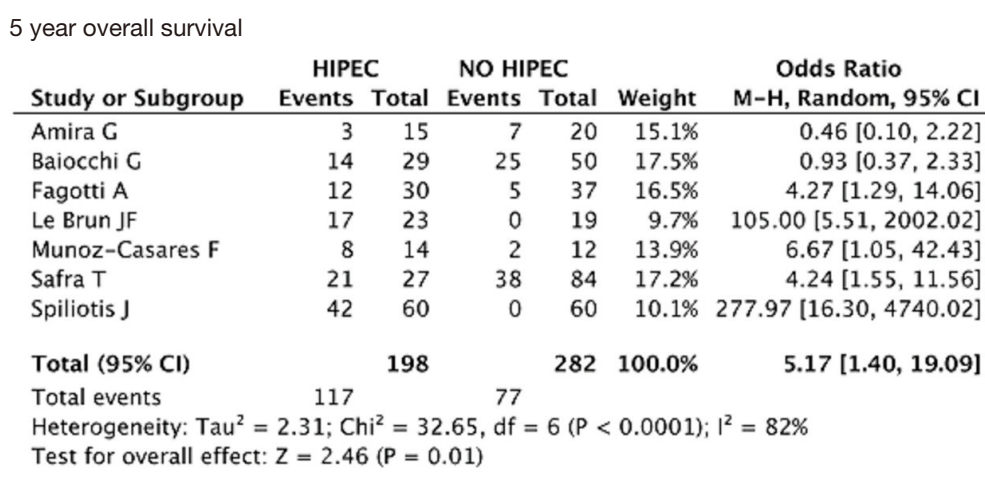

Figure 3 Two, 3, 5 years OS forest plot.

treatment seems to be safe in terms of intra-operative and post-operative complications; however, it represents an additional risk, especially related with bowel anastomosis leakage, often related to the number of surgical procedures performed. The surgery for ROC could be often less invasive than primary surgery $(21,22)$, especially for isolated abdominal relapse (23), if compared with POC. In this context, the HIPEC addition during ROC, especially for isolated relapse, could reduce the risk of complications.

However, the ROC could not be the only time to perform HIPEC, in fact, as demonstrated in some studies, the HIPEC procedures can be administered even more times during the disease history (24).

Another essential aspect that should be acknowledged is the approach adopted for HIPEC administration. In a recent study by Petrillo et al. (25), the authors completed a pharmacokinetic study in which they demonstrated that the HIPEC drugs absorption was statistically significative enhanced in patients underwent laparoscopic procedures. Probably it was related to the enhanced intra-abdominal pressure and the reduction of pressure dispersion warrantied by laparoscopy. However, considering that the endoscopic approach is not always feasible, especially for ovarian cancer treatment, some novel technologies are available and in an 
experimental phase (26-28).

\section{Conclusions}

The present systematic review and meta-analysis suggest that the HIPEC addition during cytoreductive surgery for ROC treatment can give a survival rate benefit that was recorded even after five years of follow-up.

However, the heterogeneity of the series studied cannot allow providing definitive conclusions. To date, several randomized trials are on-going with the aim to give a definitive answer to this aspect.

\section{Acknowledgments}

Funding: None.

\section{Footnote}

Provenance and Peer Review: The article was commissioned by the editorial office, Gland Surgery for the series "Ovarian Cancer Recurrence". The article has undergone external peer review.

Reporting Checklist: The authors have completed the PRISMA reporting checklist. Available at http://dx.doi. org/10.21037/gs-20-335

Peer Review File: Available at http://dx.doi.org/10.21037/gs20-335

Conflicts of Interest: All authors have completed the ICMJE uniform disclosure form (available at http://dx.doi. org/10.21037/gs-20-335). The series "Ovarian Cancer Recurrence" was commissioned by the editorial office without any funding or sponsorship. SC served as the unpaid Guest Editor of the series and serves as an unpaid editorial board member of Gland Surgery from Aug 2019 to Jul 2021. The authors have no other conflicts of interest to declare.

Ethical Statement: The authors are accountable for all aspects of the work in ensuring that questions related to the accuracy or integrity of any part of the work are appropriately investigated and resolved.

Open Access Statement: This is an Open Access article distributed in accordance with the Creative Commons
Attribution-NonCommercial-NoDerivs 4.0 International License (CC BY-NC-ND 4.0), which permits the noncommercial replication and distribution of the article with the strict proviso that no changes or edits are made and the original work is properly cited (including links to both the formal publication through the relevant DOI and the license). See: https://creativecommons.org/licenses/by-nc-nd/4.0/.

\section{References}

1. Leitao MM Jr, Chi DS. Surgical management of recurrent ovarian cancer. Semin Oncol 2009;36:106-11.

2. Tozzi R, Giannice R, Cianci S et al. Neo-adjuvant chemotherapy does not increase the rate of complete resection and does not significantly reduce the morbidity of Visceral-Peritoneal Debulking (VPD) in patients with stage IIIC-IV ovarian cancer. Gynecol Oncol 2015;138:252-8.

3. Bristow RE, Tomacruz RS, Armstrong DK, et al. Survival effect of maximal cytoreductive surgery for advanced ovarian carcinoma during the platinum era: a metaanalysis. J Clin Oncol 2002;20:1248-59.

4. Paris I, Cianci S, Vizzielli G et al. Upfront HIPEC and bevacizumab- containing adjuvant chemotherapy in advanced epithelial ovarian cancer. Int J Hyperthermia 2018;35:370-4.

5. Issels RD. Hyperthermia adds to chemotherapy. Eur J Cancer 2008;44:2546-54.

6. van Driel WJ, Koole SN, Sikorska K, et al. Hyperthermic intraperitoneal chemotherapy in ovarian cancer. $\mathrm{N}$ Engl J Med 2018;378:230-40.

7. Moher D, Liberati A, Tetzlaff J, et al. Preferred reporting items for systematic reviews and meta-analyses: the PRISMA statement. J Clin Epidemiol 2009;62:1006-12.

8. Stroup DF, Berlin JA, Morton SC, et al. Meta-analysis of observational studies in epidemiology: a proposal for reporting. Meta-analysis Of Observational Studies in Epidemiology (MOOSE) group. JAMA 2000;283:2008-12.

9. Spiliotis J, Halkia E, Lianos E, et al. Cytoreductive surgery and HIPEC in recurrent epithelial ovarian cancer: a prospective randomized phase III study. Ann Surg Oncol 2015;22:1570-5.

10. Fagotti A, Costantini B, Petrillo M, et al. Cytoreductive surgery plus HIPEC in platinum-sensitive recurrent ovarian cancer patients: a case-control study on survival in patients with two year follow-up. Gynecol Oncol 2012;127:502-5.

11. Safra T, Grisaru D, Inbar M, et al. Cytoreduction surgery 
with hyperthermic intraperitoneal chemotherapy in recurrent ovarian cancer improves progression-free survival, especially in BRCA-positive patients- a casecontrol study. J Surg Oncol 2014;110:661-5.

12. Le Brun JF, Campion L, Berton-Rigaud D, et al. Survival benefit of hyperthermic intraperitoneal chemotherapy for recurrent ovarian cancer: a multi-institutional case control study. Ann Surg Oncol 2014;21:3621-7.

13. Baiocchi G, Ferreira FO, Mantoan H, et al. Hyperthermic Intraperitoneal Chemotherapy after Secondary Cytoreduction in Epithelial Ovarian Cancer: A Single-center Comparative Analysis. Ann Surg Oncol 2016;23:1294-301.

14. Amira G, Morsi A, Fayek IS, et al. Hyperthermic Intraperitoneal Chemotherapy Versus Systemic Chemotherapy in Recurrent Platinum-Sensitive Ovarian Cancer NCI Case Control Study. Asian Pac J Cancer Prev 2019;20:621-7.

15. Muñoz-Casares FC, Rufián S, Rubio MJ, et al. The role of hyperthermic intraoperative intraperitoneal chemotherapy (HIPEC) in the treatment of peritoneal carcinomatosis in recurrent ovarian cancer. Clin Transl Oncol 2009;11:753-9.

16. Chiva LM, Gonzalez-Martin A. A critical appraisal of hyperthermic intraperitoneal chemotherapy (HIPEC) in the treatment of advanced and recurrent ovarian cancer. Gynecol Oncol 2015;136:130-5.

17. Petrillo M, De Iaco P, Cianci S, et al. Long-term survival for platinum-sensitive recurrent ovarian cancer patients treated with secondary cytoreductive surgery plus hyperthermic intraperitoneal chemotherapy (HIPEC). Ann Surg Oncol 2016;23:1660-5.

18. Huo YR, Richards A, Liauw W, et al. Hyperthermic intraperitoneal chemotherapy (HIPEC) and cytoreductive surgery (CRS) in ovarian cancer: A systematic review and meta-analysis. Eur J Surg Oncol 2015;41:1578-89.

19. Harter P, Beutel B, Alesina PF, et al. Prognostic and predictive value of the Arbeitsgemeinschaft Gynaekologische Onkologie (AGO) score in surgery for recurrent ovarian cancer. Gynecol Oncol 2014;132:537-41.

20. Zang RY, Harter P, Chi DS, et al. Predictors of survival in patients with recurrent ovarian cancer undergoing secondary cytoreductive surgery based on the pooled analysis of an international collaborative cohort. Br J Cancer 2011;105:890-6.

21. Gueli Alletti S, Vizzielli G, Lafuenti L, et al. Single-
Institution Propensity-Matched Study to Evaluate the Psychological Effect of Minimally Invasive Interval Debulking Surgery Versus Standard Laparotomic Treatment: From Body to Mind and Back. J Minim Invasive Gynecol 2018;25:816-22.

22. Gallotta V, Conte C, Giudice MT, et al. Secondary Laparoscopic Cytoreduction in Recurrent Ovarian Cancer: A Large, Single-Institution Experience. J Minim Invasive Gynecol 2018;25:644-50.

23. Fagotti A, Costantini B, Gallotta V, et al. Minimally invasive secondary cytoreduction plus HIPEC versus open surgery plus HIPEC in isolated relapse from ovarian cancer: a retrospective cohort study on perioperative outcomes. J Minim Invasive Gynecol 2015;22:428-32.

24. Cianci S, Ronsini C, Vizzielli G, et al. Cytoreductive surgery followed by HIPEC repetition for secondary ovarian cancer recurrence. Updates Surg 2019;71:389-94.

25. Petrillo M, Zucchetti M, Cianci S, et al. Pharmacokinetics of cisplatin during open and minimally-invasive secondary cytoreductive surgery plus HIPEC in women with platinum-sensitive recurrent ovarian cancer: a prospective study. J Gynecol Oncol 2019;30:e59.

26. Cianci S, Abatini C, Fagotti A, et al. Hyperthermic intraperitoneal chemotherapy (HIPEC) for peritoneal malignancies using new hybrid CO2 system: preliminary experience in referral center. Updates Surg 2019;71:555-60.

27. Cianci S, Vizzielli G, Fagotti A, et al. A novel HIPEC technique using hybrid $\mathrm{CO} 2$ recirculation system: intraabdominal diffusion test in a porcine model. Updates Surg 2018;70:529-33.

28. Bakrin N, Tempfer C, Scambia G, et al. PIPAC-OV3: A multicenter, open-label, randomized, two-arm phase III trial of the effect on progression-free survival of cisplatin and doxorubicin as Pressurized Intra-Peritoneal Aerosol Chemotherapy (PIPAC) vs. chemotherapy alone in patients with platinum-resistant recurrent epithelial ovarian, fallopian tube or primary peritoneal cancer. Pleura Peritoneum 2018;3:20180114.

Cite this article as: Cianci S, Riemma G, Ronsini C, De Franciscis P, Torella M, Schiattarella A, La Verde M, Colacurci N. Hyperthermic intraperitoneal chemotherapy (HIPEC) for ovarian cancer recurrence: systematic review and meta-analysis. Gland Surg 2020;9(4):1140-1148. doi: 10.21037/gs-20-335 
Supplementary

Table S1 Quality scores of the case-control studies included in the meta-analysis, assessed by the Newcastle-Ottawa scale

\begin{tabular}{|c|c|c|c|c|c|c|c|c|c|c|c|c|}
\hline \multirow[b]{2}{*}{ Author } & \multirow[b]{2}{*}{ Year } & \multirow[b]{2}{*}{ Outcome } & \multicolumn{4}{|c|}{ Selection } & \multicolumn{2}{|c|}{ Comparability } & \multicolumn{3}{|c|}{ Exposure } & \multirow{2}{*}{$\begin{array}{l}\text { Overall } \\
\text { quality }\end{array}$} \\
\hline & & & $\begin{array}{c}\text { Case } \\
\text { definition }\end{array}$ & $\begin{array}{l}\text { Representative- } \\
\text { ness of the cases }\end{array}$ & $\begin{array}{l}\text { Selection of } \\
\text { controls }\end{array}$ & $\begin{array}{l}\text { Definition of } \\
\text { controls }\end{array}$ & $\begin{array}{l}\text { Control for the most } \\
\text { important factor }\end{array}$ & $\begin{array}{l}\text { Control for any } \\
\text { additional factors }\end{array}$ & $\begin{array}{l}\text { Ascertainment of } \\
\text { exposure }\end{array}$ & $\begin{array}{l}\text { Same method for } \\
\text { cases and controls }\end{array}$ & $\begin{array}{l}\text { Non- } \\
\text { response rate }\end{array}$ & \\
\hline Safra T & 2014 & $\begin{array}{l}\text { Overall } \\
\text { survival }\end{array}$ & * & * & 0 & 0 & * & * & * & * & 0 & 6 \\
\hline Fagotti A & 2012 & $\begin{array}{l}\text { Overall } \\
\text { survival }\end{array}$ & * & * & * & * & * & * & * & * & 0 & 8 \\
\hline Baiocchi G & 2016 & $\begin{array}{l}\text { Overall } \\
\text { survival }\end{array}$ & * & * & * & * & * & * & 0 & * & * & 8 \\
\hline $\begin{array}{l}\text { Muñoz- } \\
\text { Casares FC }\end{array}$ & 2009 & $\begin{array}{l}\text { Overall } \\
\text { survival }\end{array}$ & * & * & 0 & 0 & * & * & 0 & * & 0 & 5 \\
\hline Le Brun JF & 2014 & $\begin{array}{l}\text { Overall } \\
\text { survival }\end{array}$ & * & * & 0 & * & * & * & * & * & * & 8 \\
\hline
\end{tabular}

Newcastle-Ottawa scale for assessment of quality of included studies-case-control studies (each asterisk represents if individual criterion within the subsection was fulfilled).

Table S2 Quality assessment for RCTs (method: Cochrane collaboration's tool for assessing risk of bias)

\begin{tabular}{|c|c|c|c|c|c|c|c|c|}
\hline \multirow[t]{2}{*}{ Author } & \multicolumn{2}{|c|}{ Selection bias } & \multirow{2}{*}{$\begin{array}{c}\text { Performance bias } \\
\text { Binding of participant } \\
\text { and personnel }\end{array}$} & \multirow{2}{*}{$\begin{array}{c}\text { Detection bias } \\
\begin{array}{c}\text { Blinding of outcome } \\
\text { assessment }\end{array}\end{array}$} & \multirow{2}{*}{$\begin{array}{c}\text { Attrition bias } \\
\begin{array}{c}\text { Incomplete outcome } \\
\text { data }\end{array}\end{array}$} & \multirow{2}{*}{$\begin{array}{c}\text { Reporting bias } \\
\text { Selective reporting }\end{array}$} & \multirow{2}{*}{$\begin{array}{c}\text { Other bias } \\
\begin{array}{c}\text { Anything else, ideally } \\
\text { prespecifed }\end{array}\end{array}$} & \multirow{2}{*}{$\begin{array}{c}\text { Total } \\
\text { Low on risk of bias }\end{array}$} \\
\hline & $\begin{array}{l}\text { Random sequence } \\
\text { generation }\end{array}$ & $\begin{array}{l}\text { Allocation } \\
\text { concealment }\end{array}$ & & & & & & \\
\hline Spiliotis J & Low & Low & Low & Low & Unclear & Unclear & Low & $5 / 7$ \\
\hline
\end{tabular}

$\mathrm{RCTs}$, randomized controlled trials. 